\title{
the dynamics investigated in situ in milk in relation to temperature and time
}

\section{O. Et Thakafy, F. Guyomarc'h, C. Lopez}

Science and Technology of Milk and Eggs (STLO), UMR 1253, INRA, Agrocampus Ouest, Rennes, France

\author{
Christelle.Lopez@inra.fr
}

\section{The milk fat globule membrane (MFGM)}

Milk is an emulsion of fat droplets stabilized by a biological membrane called the milk fat globule membrane (MFGM; Figure 1). The MFGM is mainly composed of polar lipids that have different melting temperatures $\left(T_{m}\right)$, cholesterol, glycoproteins, and enzymes. The microstructure of the MFGM depends on the packing of polar lipids in the outer bilayer of the membrane that can lead to phase separation with formation of ordered domains (Figure 2). Milk is usually submitted to changes in temperature e.g. storage $\left(4-7^{\circ} \mathrm{C}\right)$, churning $\left(10-12^{\circ} \mathrm{C}\right)$ and heat treatments (e.g. pasteurization). Do these temperature variations and thermal history of milk affect the packing of polar lipids in the plane of the MFGM ?

Experiments were performed by confocal laser scanning microscopy (CLSM) under temperature controlled conditions, using the head-labelled phospholipid fluorescent probe Rh-DOPE. Only the fluid phase of MFGM was labelled.

Milk: oil/water emulsion

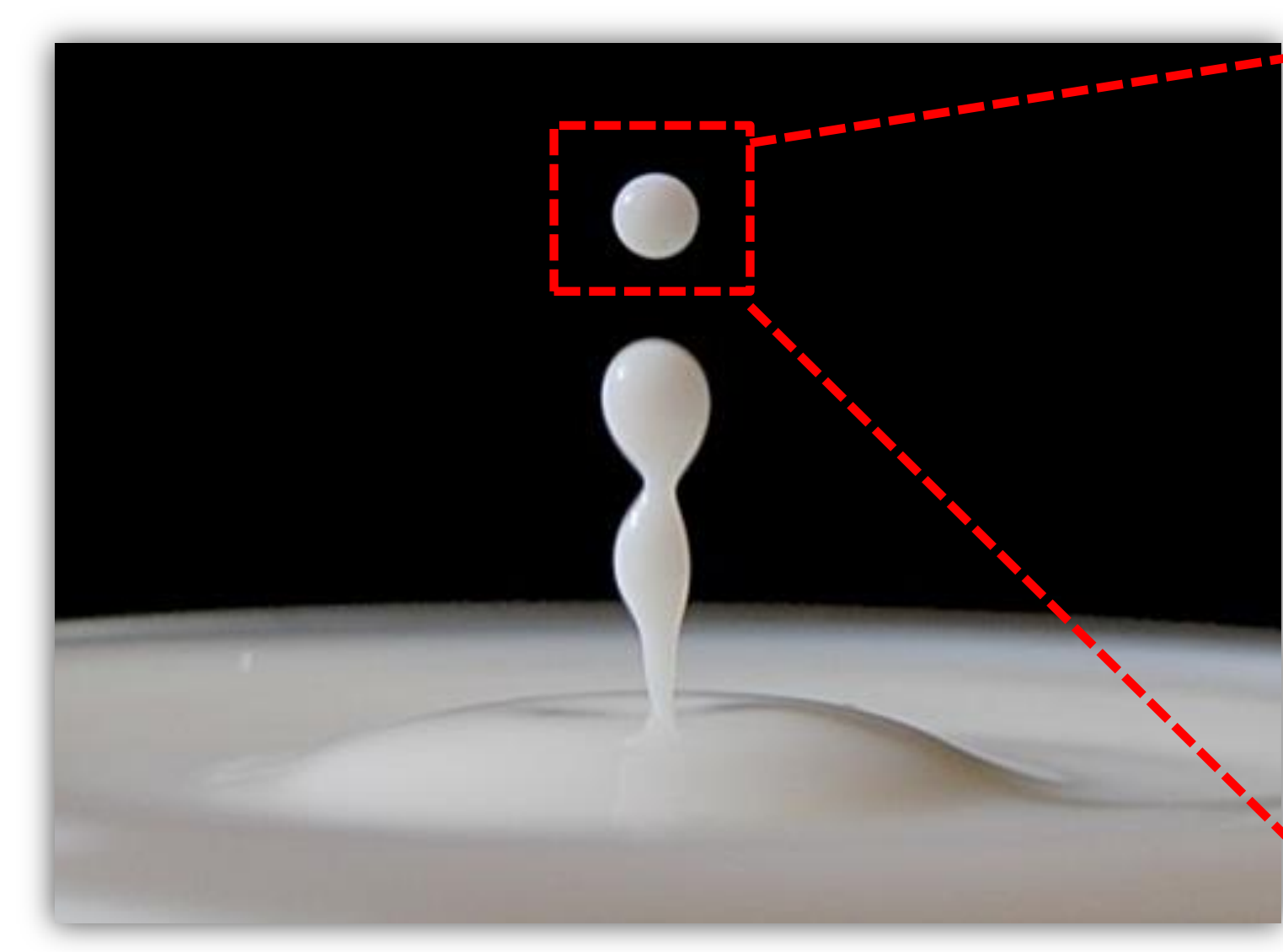

$\underline{\text { Fig.1 }}$
Milk fat globules

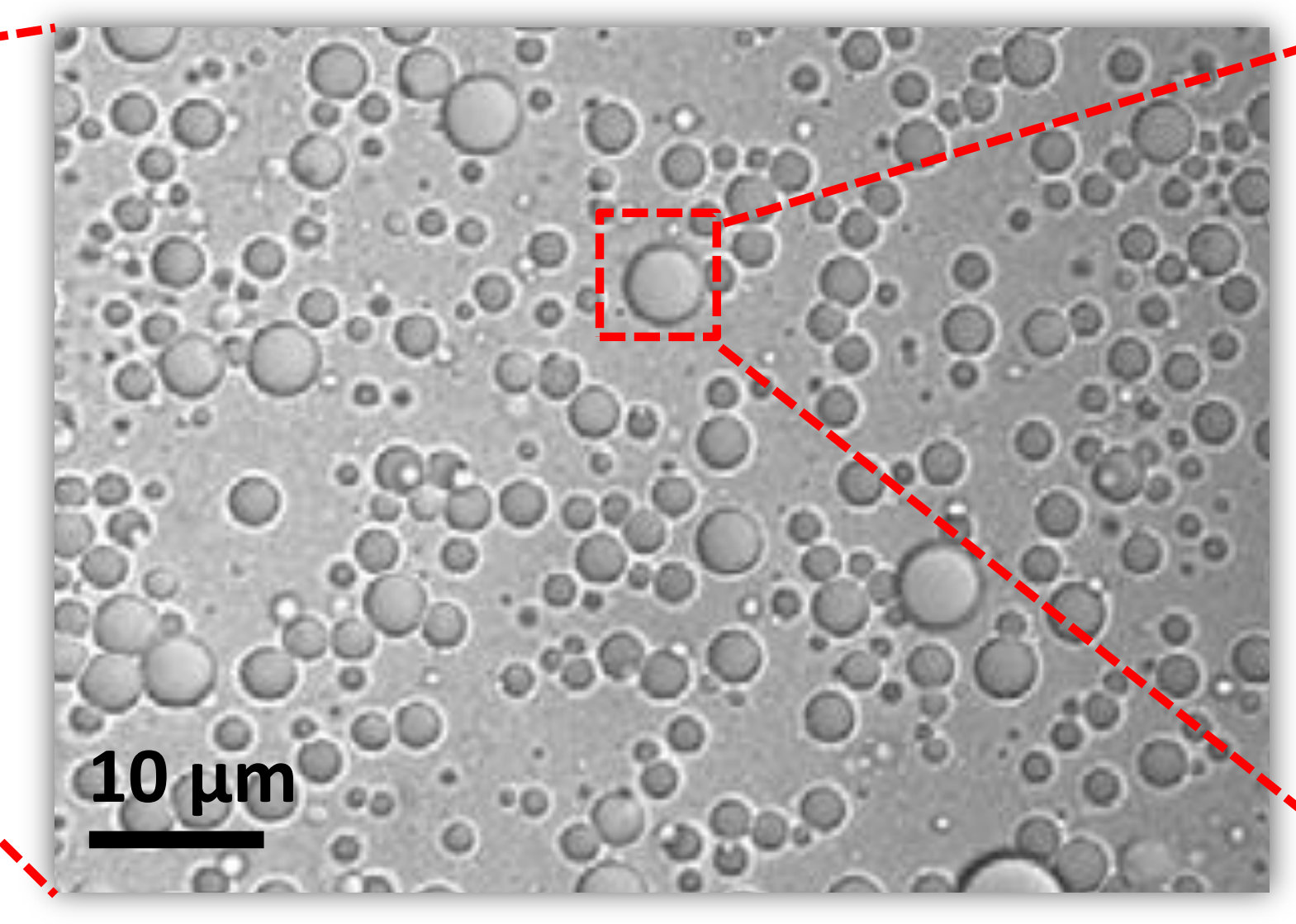

Differential interference contrast (DIC) microscopy
MFGM enveloping fat globules

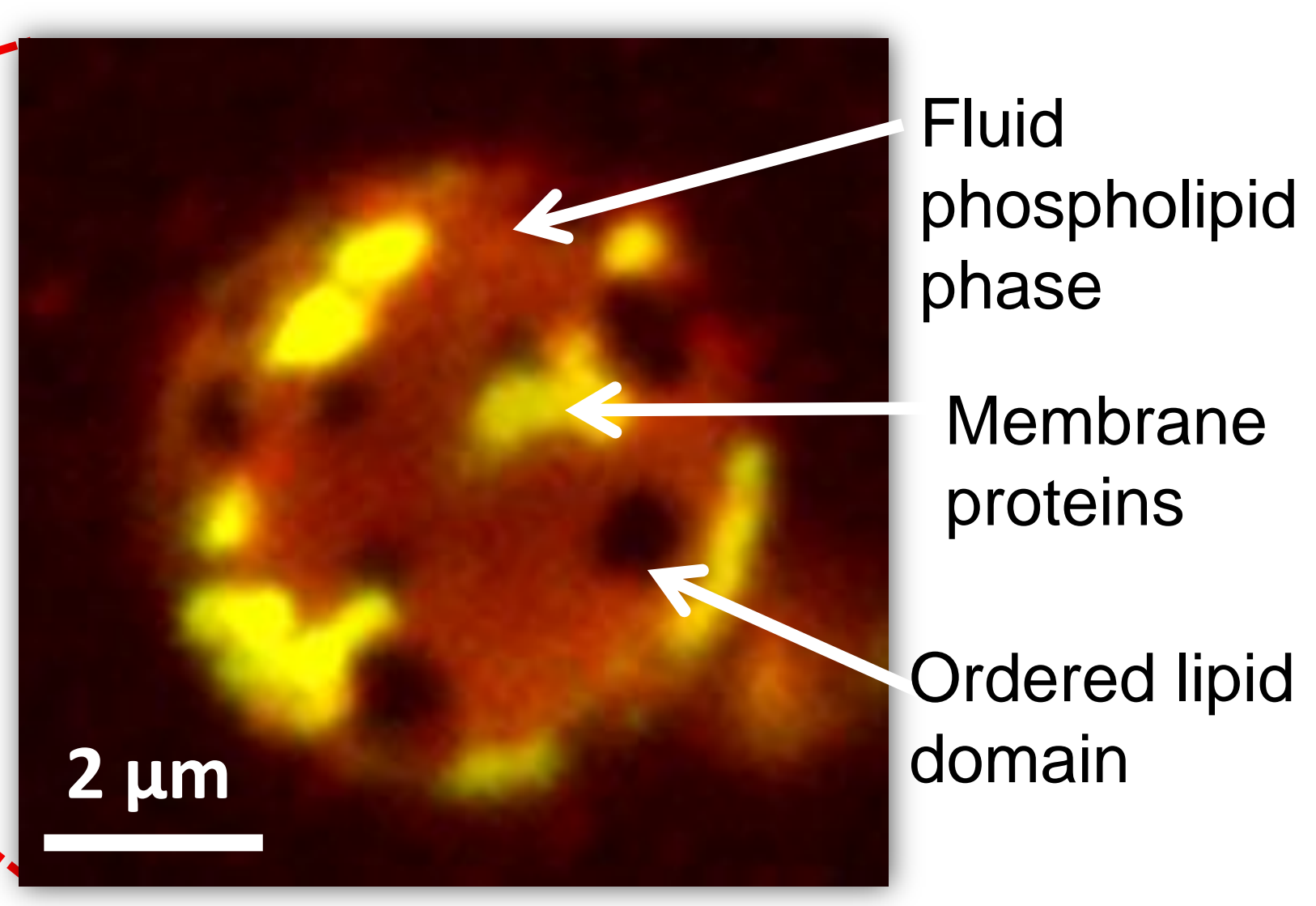

confocal laser scanning microscopy
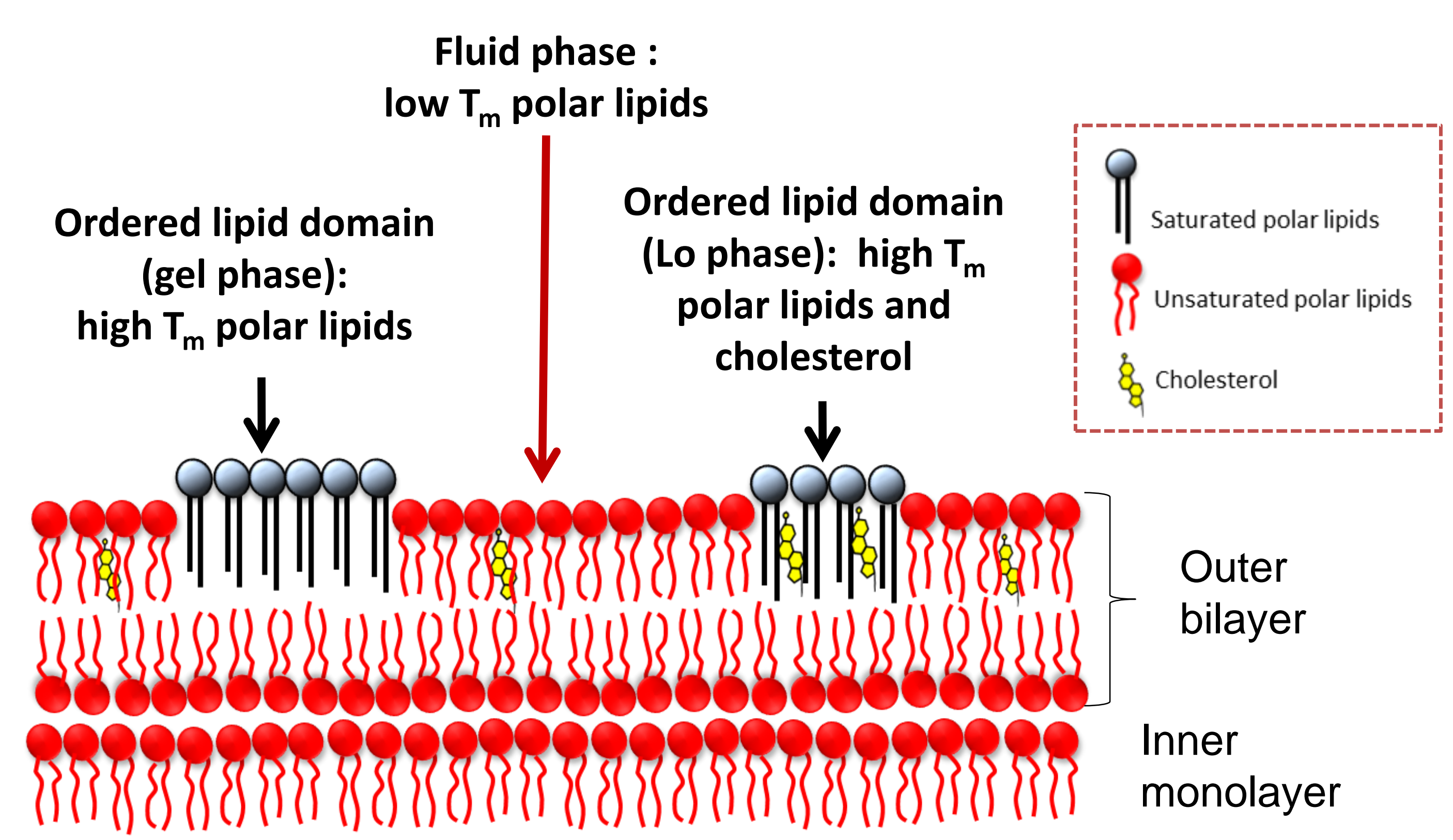

Fig.2

2D representation of the MFGM

\section{Dynamics and reorganization of MFGM polar lipids investigated upon milk heating or cooling}

Heating of milk favors the diffusion of the lipid domains, coalescence, reduction in size

or complete melting of the polar lipids (disappearance of domains)

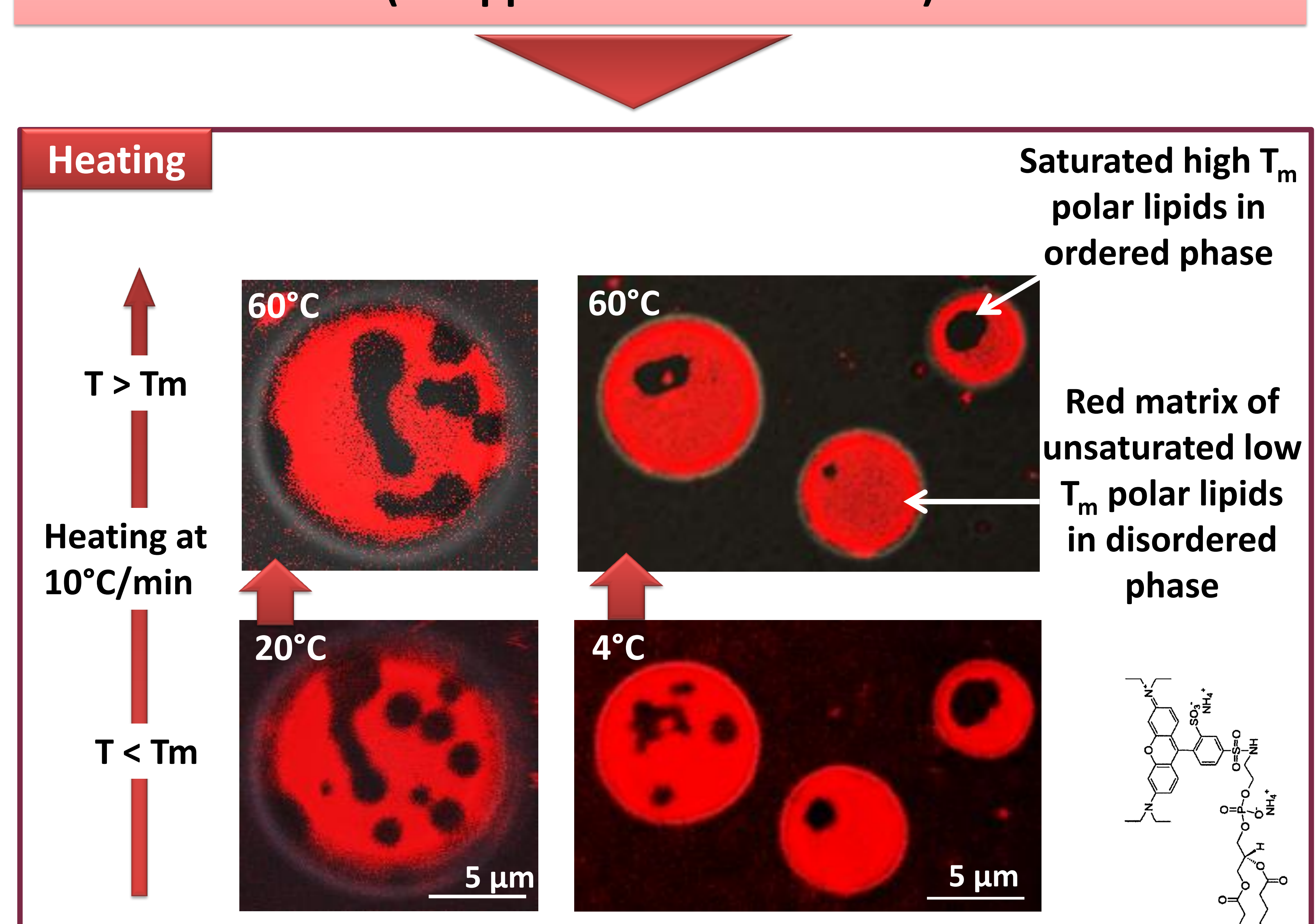

The disappearance of domains at $60^{\circ} \mathrm{C}$ was interpreted as gel to fluid phase transition of the saturated high $\mathrm{T}_{\mathrm{m}}$ polar lipids. Meanwhile, the domains present at $60^{\circ} \mathrm{C}$ must be in liquid ordered (Lo) phase due to the involvement of cholesterol.
Rapid cooling of milk from $60^{\circ} \mathrm{C}$ favors the appearance of small elongated domains while extended storage induces lipid reorganizations within the MFGM

with growth leading to large circular lipid domains

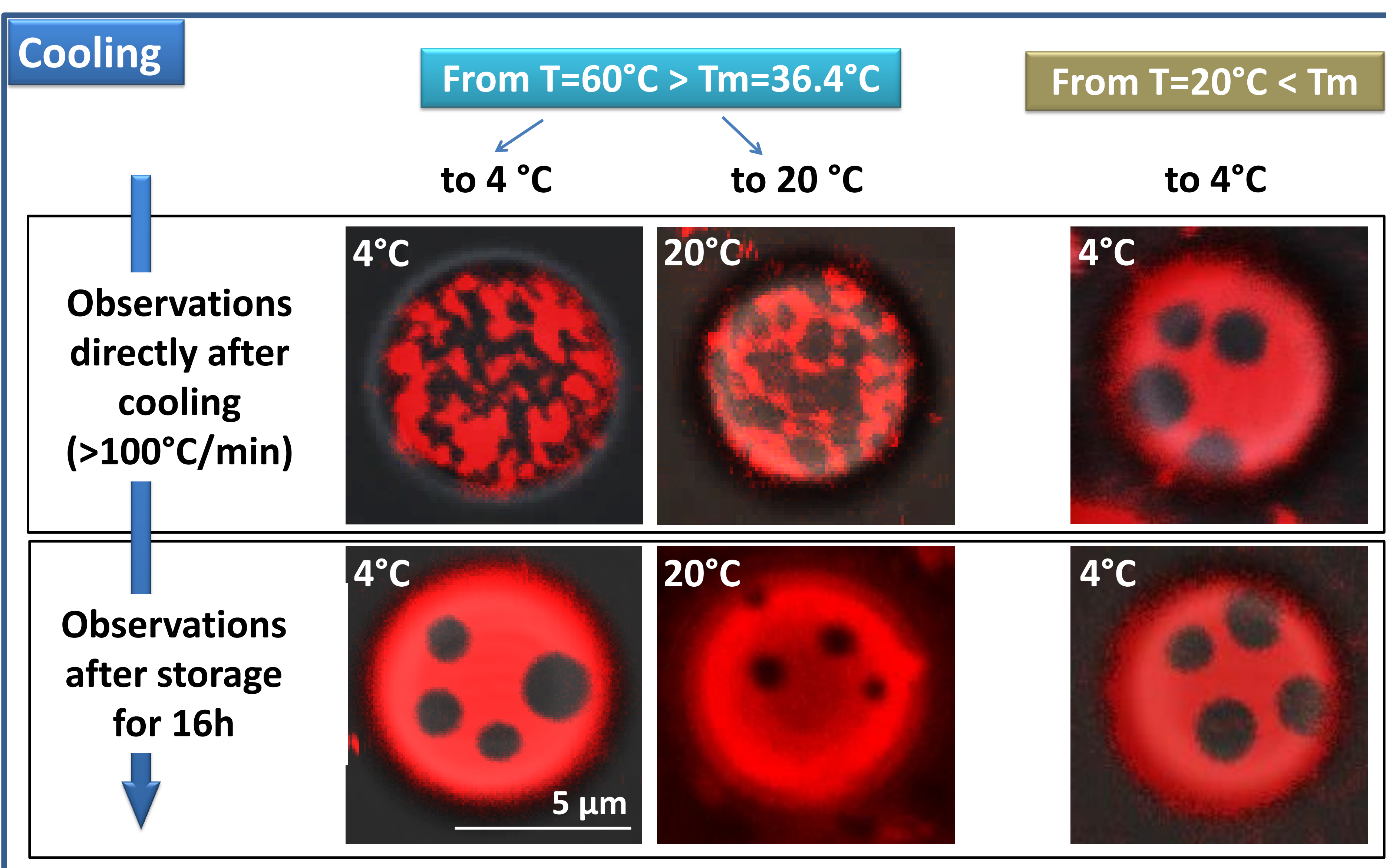

After cooling from $60^{\circ} \mathrm{C}$, the formation of small elongated domains at the surface of milk fat globules was interpreted as fluid to gel phase transition of the saturated high $\mathrm{T}_{\mathrm{m}}$ polar lipids.

Cooling from $20^{\circ} \mathrm{C}$ had no effect on lipid domains (circular shape \& number), which was probably due to the fact that the temperature quench of $20^{\circ} \mathrm{C}$ did not encompass the $T_{m}$ of the MFGM polar lipids.

\section{Conclusion \& Outlooks:}

This study demonstrates that the packing of polar lipids within the MFGM strongly depends on the temperature and the thermal history of milk. Changes in the morphology and physical properties of the lipid domains induced by temperature and time could affect many interfacial mechanisms involved in e.g. lipid digestion, adsorption of enzymes, bacteria or viruses, localization of proteins, and could also alter the physical stability of fat globules during milk processing.

Et Thakafy, O., F. Guyomarc'h \& Lopez, C. Lipid domains in the milk fat globule membrane: the dynamics investigated in situ in milk in relation to temperature and time. Food Chemistry. DOI.10.1016/j.foodchem.2016.10.017

IDF World Dairy Summit, 16-21 October 2016 Rotterdam, The Netherlands

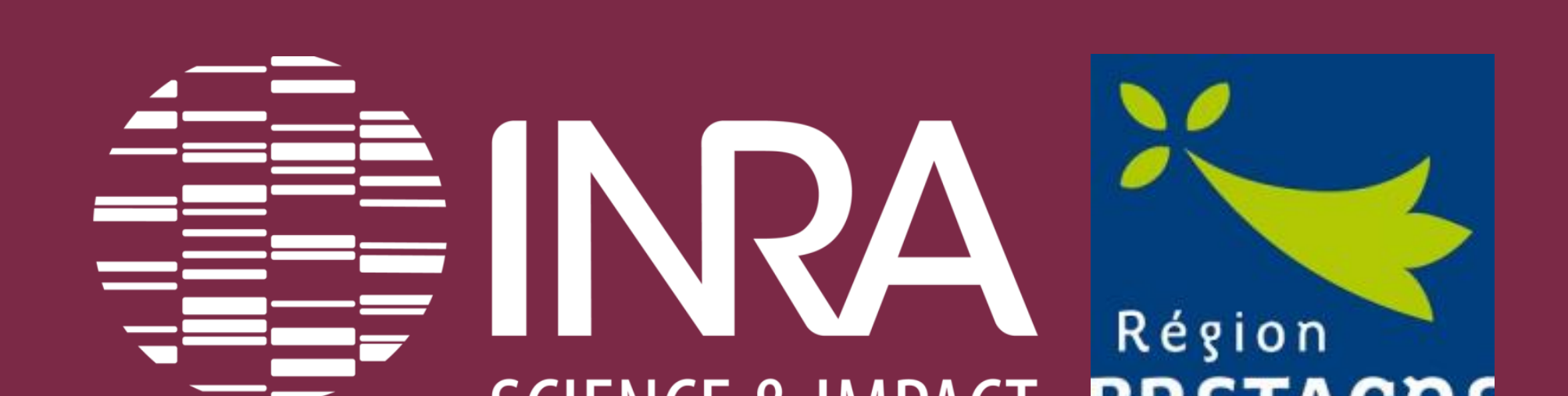

SCIENCE \& IMPACT BRETAGNE
INRA - Agrocampus Ouest

Science and Technology of Milk and Eggs

Rennes, FRANCE

www.rennes.inra.fr/stlo 